globulin chains, the molecular changes associated with the regulation of mating type in yeast and so on). In short, the early sections are strong on the classic things, but appear a bit dated.

The chapters on the functioning of organisms do a good job of covering the major problems faced and solved by higher organisms: nutrition and gas exchange, transport, hormone functioning and the like. The emphasis is strongly on human biology (again with excellent illustrations), with occasional genuflection toward comparative and evolutionary analyses.

The concluding chapters focus on the broad themes of evolutionary thinking: the history of the subject, micro- and macroevolution, biogeography and the fossil record. No other introductory text treats this material so thoroughly or so well. These chapters expound the essential philosophical character of Darwin's theory, and discuss problems associated with it, both past (blending inheritance; Mivart's doubts about the evolution of the incipient stages of useful structures, as instanced by the two reptilian jaw bones that are ear bones in contemporary mammals) and present ("neutral evolution"; mechanisms that can maintain heterozygosity in populations; cladist, phenetic and classical evolutionary schools of taxonomy). Given the current misrepresentation of evolutionary thinking by the so-called "scientific" creationists, these chapters are especially valuable. They are marred only by an occasional tendency to intrusive editorial comment, and by the misrepresentation of Darwin as holding that evolution proceeds at a consistently gradual rate, in contrast with contemporary notions about "punctuated equilibrium". As observed by Andrew Huxley in his Presidential Address to the Royal Society last year, Darwin's statement that "each form remains for long periods unaltered, and then again undergoes modification"' and

the periods during which species have been undergoing modification, though very long as measured by years, have probably been short in comparison with the periods during which these same species remained without undergoing any change . .

effectively makes him a punctuated equilibrist.

The treatment of population genetics is brief and not well organized, and that of population biology and ecology is perfunctory.

In short, this is a distinctive introductory biology text that all teachers of such courses will profit from reading. But we feel it is a bit too thin and quirky to displace the canonical Curtis or Keeton, unless supplemented by extensive additional readings.

Edward C. Cox is Chairman of, and Robert $M$. May Professor in, the Biology Department at Princeton University, where they jointly teach an introductory biology course.

\title{
The multifarious questions of evolution
}

\section{Bentley Glass}

Understanding Evolution. By Earl D. Hanson. Pp.556. ISBN 0-19-502784-1. (Oxford University Press: 1981.) £14.95, $\$ 23.95$.

THE recent flurry of attacks on school textbooks and the teachers of biology who deal with evolution should focus attention on the college textbooks of evolution and the way in which the subject is taught. The questions to be asked are multifarious. Is organic evolution itself, as distinct from the mechanism of natural selection, a theory or a fact? Is adequate attention given to the gradual change of ideas about a theory, starting in the case of evolution with the first glimmerings of the concept among the Greek philosophers and the ancient and mediaeval belief in spontaneous generation? What of the long debate over the inheritance of acquired characteristics, continuing even today? Just what was Darwin's contribution to the theory of evolution? How does the evolutionary synthesis of today differ from Darwin's own ideas? There are many more.

In most respects, the teacher - if not the student - will welcome Hanson's book. It is comprehensive and clearly written. As might be expected from his earlier books, Hanson emphasizes animal and plant diversity, homologies and relationships. But there is a substantial section devoted to Mendelian and modern genetics as the basis of understanding what Darwin always affirmed was the crux of the matter: the nature and origin of hereditary variations. There is also a detailed treatment of the evidence for relationships that comes from biochemical comparisons of amino acid sequences in proteins and nucleotide sequences in DNA. For a course intended to run only for one semester of a college year, there may be far more technical detail here than a student can master; yet better too much than too skimpy a treatment.

As for noticeable deficiencies in the book, it seems to me that not enough attention is given to the history of the idea of evolution, to the pre-Darwinian as well as post-Darwinian gropings for an explanation of origins, to the marvellous combination of evidence from every sub-field of biology. I notice also a tendency to deal rather briefly with the evolution of plants, although their speciation by polyploidy, especially allopolyploidy, affords some of the best evidence for the origin of species in recent times. The coverage of plant and animal geography in relation to evolution is also somewhat meagre. Nevertheless, the classical evolutionary synthesis is well expounded.

Finally, in respect to human evolution, in my opinion a fuller development of primate and hominid evolution would be enjoyed by teacher and students alike. It is difficult, in this area of knowledge, to keep pace with discovery and choose between conflicting interpretations. Hanson has relied heavily on the work of the Leakeys. $\mathrm{He}$ omits entirely any reference to the breathtaking discovery of "Lucy", the three-million-year-old, erect-walking australopithecine whose complete skeleton is the most magnificent and astounding of all palaeoanthropological discoveries. This section of Hanson's book already cries out for revision.

The last 200 pages of Understanding Evolution are devoted to a phylogenetic survey of plant and animal groups. That is clearly the author's own bent. Other teachers may wish that those pages had been used for a fuller treatment of some of the matters I have mentioned that have received little attention. In particular, there would be a solid advantage in allotting space to an explicit exposé of the assumptions and subterfuges of the "scientific" creationists.

Bentley Glass is Distinguished Professor of Biology Emeritus at the State University of New York, Stony Brook.

\section{Natural history of vertebrates}

\section{Barry Cox}

Patterns of Vertebrate Biology. By E.W. Jameson, Jr. Pp.477. ISBN 0-387-90520-0. (Springer-Verlag: 1981.) DM 63, \$33.20.

THE preface to Jameson's book states that it is concerned with the natural history of vertebrates, and he comments that "the laboratory, however essential and productive, is a departure from the animal's real world'. Much of the book is therefore primarily descriptive, made up of a collection of discussions of different aspects of the field biology of vertebrates.

However, Jameson commences with chapters concerned with "An Overview of Vertebrate Phylogeny", "Mechanics of Evolution" and "Zoogeography". It is always difficult to know where to draw the line between relevant topics and those which are merely general background, but I thought that none of these contributed significantly to Jameson's main thesis, while the first also revealed an uncertain knowledge and understanding of this topic.

The remainder of the book is divided into three parts: "Individual Environ- 